\title{
Control of Hybrid Energy Storage System for Hybrid Electric Vehicles using Uniform Continuous Higher Order Sliding Mode Control
}

\author{
Prasanth K Prasad \\ Research Scholar \\ Department of Electrical and Electronics Engineering, \\ Government Enginering College, Thrissur, \\ Kerala, India 680009. \\ Affiliated to APJ Abdul Kalam Technological University, \\ email: prasanthkprasad@gectcr.ac.in
}

\author{
Ramesh Kumar P \\ Assistant Professor \\ Department of Electrical and Electronics Engineering, \\ Government Enginering College, Thrissur, \\ Kerala, India 680009. \\ Affiliated to APJ Abdul Kalam Technological University, \\ email: rameshp36@gmail.com
}

\begin{abstract}
The goal of this paper is to control a fully active hybrid energy storage System (HESS) with a battery and super capacitor (SC) by introducing an uniform higher order sliding mode control. The system parameters to be tracked are the battery and SC current. To track the reference values of battery and SC currents, an uniform continuous higher order sliding mode controller (UCHOSMC) is applied which is a combination of two controllers one is an uniform super twisting control for disturbance rejection and other is uniform time convergence for a disturbance free system. Current references to be tracked are generated by a rule-based energy management system, the stability of the system is validated using Lyapunov stability analysis. The simulation results show the robustness of the controller with an effective tracking of the reference values under different load conditions.

Index Terms-Electric vehicles (EV), Hybrid energy storage system (HESS), Uniform continuous higher order sliding mode controller (UCHOSMC), Battery-super capacitor.
\end{abstract}

\section{INTRODUCTION}

In the present scenario, energy consumption has increased dramatically as a result of advancements in the field of lifestyle technology and transportation. The majority of countries use fossil fuel as their principal source to meet their energy needs in automobiles [1].

The obvious alternative to the global energy crisis is hybrid electric vehicles (HEVs) which can ensure sustainable transportation with clean mobility emission mitigation and reduced resource utilization [2], [3]. The challenge of their emergence is a high-capacity energy storage system that controls the performance and cruising range of electric vehicles. Energy is consumed by the battery during charging, and the energy is released from the battery during driving period.

Since the energy storage unit in HEVs endure intermittent charging and discharging conditions and as a result, unintended battery deterioration occurs, leading to a reduction in battery life [4], [5]. On the contrary, the energy storage device like the super capacitor (SC) has an immense life cycle relative to the battery. By integrating SC with the battery, the hybrid energy storage system (HESS) can be introduced, adding benefits that cope with current spikes and regular charging and discharging [6], [7], [8]. HESS takes advantage of the SC's potential, which offers a relatively high power density and a fast response time to ensure the safety of the battery [9]. HESS is thus known to be one of the most effective sources of energy for EVs [10].

HESS can be categorized into three groups: passive, semiactive and fully active types. The passive HESS aligns the battery and SC in parallel and is connected directly to the DC bus [11]. Passive HESS has a basic topology and is relatively simple to implement in EVs. Saving one or two high-power DC-DC converters will result in substantial cost savings for the EV system. When cost is taken into account, passive HESS is a solid option.

In semi-active HESS, power electronic converters are used between the SC or battery elements and the DC bus in order to allow better use of HESS elements. This enables active control of the power flow. Only one of the two HESS elements is actively controlled with semi-active HESS. This topology which ensures better performance when compared with passive HESS, and it has a good performance-cost balance [12], [13].

In fully-active HESS, the power flow of the battery and SC are both actively controlled via bidirectional DC/DC converters in full active HESS topology [14], [15]. This improves the HESS's flexibility and enhances the system's overall efficiency and life cycle. Through a carefully designed control strategy, this topology can improve efficiency, battery life, and DC bus stability. A fully active HESS is shown in Fig. 1.

Different methods of energy management system (EMS) have been used in order to safeguard the SC and battery. Some type of EMS are, rule based strategy (RBS) [16], filtration based strategy [17], model predictive strategy [18], fuzzy logic strategy [5], "all or nothing" strategy [19], and global optimization strategy like dynamic programming (DP) [20] and Poynting's minimum principle [6]. These EMS strategies produce battery and SC current references through optimal 


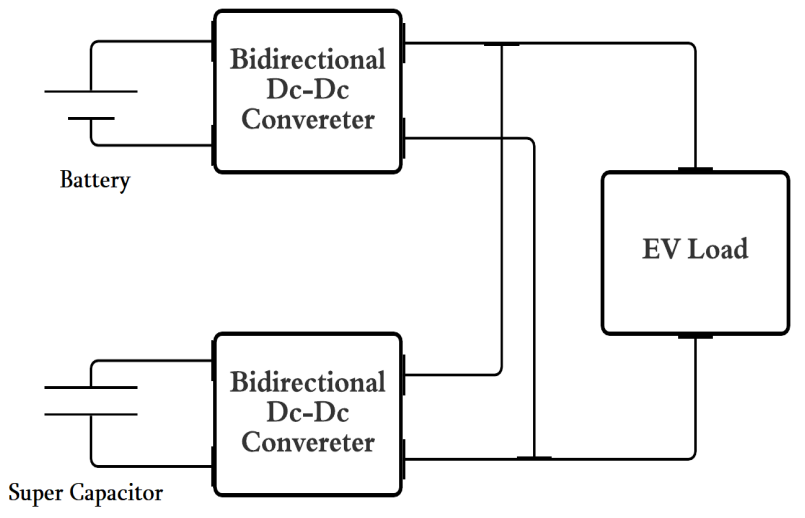

Fig. 1. Fully-Active HESS.

power demand allocation. Upon receiving the current reference, the controller is designed to regulate the necessary power flow from the battery and the SC to follow the desired drive pattern.

As far as the controller is concerned, the conventional PID controller will provide high reliability and will be relatively simple to realize. The drawback is that, due to local linearization the performance may degrade at different operating conditions [21]. In this contest, non-linear control methodologies have been proposed to address this challenge [22], [23], [24]. A conventional sliding mode control with a Lyapunov-based control function is proposed in [22] to monitor the reference created by EMS and to control the bus voltage. In [23] an estimator based adaptive SMC is proposed, which can estimate load variance and disturbances by state observers and Lyapunov function. The problem of control design is transferred into a numerical optimization problem with linear matrix inequality (LMI) constraints in [24]. Twostate feedback law is used in LMI to control battery current and bus voltage.

The advantage of using SMC is that, by rejecting external disturbances, it can stabilize non-linear systems and ensure robust reference parameter tracking. The down sides are, the presence of discontinuous control action, which can lead to chattering effect and result in improper system performance. To mitigate the chattering phenomenon, a higher order sliding mode controller can be used [25]. There are several algorithms available to realize HOSMC, some of them are sub-optimal controller, terminal sliding mode controller, twisting algorithm based HOSMC, super twisting algorithm based HOSMC. Among this super twisting algorithm guarantees continuous control action with assured robustness for the system.

In this paper, a new controller called uniform continuous higher order sliding mode controller is applied which is a combination of a super-twisting controller intended for disturbance rejection and a controller designed to ensure uniform finite time convergence in the absence of disturbance. The ro- bustness of the controller is simulated in MATLAB/Simulink.

The remaining portion of the paper is organized as follows: Section II addresses HESS and its state equations. The rule based energy management system (EMS) is described in Section III. Section IV investigates the principle of super twisting algorithm. In Section V, the uniform continuous higher order sliding mode control for HESS is explained. Section VI shows simulation results and inference. In the end, section VII gives conclusion and inference from the controller.

\section{HESS MODELLING}

Fully active HESS is preferred in EVs due to its inherent flexibility. The schematic diagram of HESS is shown in Fig. 2. The HESS system consists of two separate sources, one of which is a battery source and the other is a super capacitor pack, and a bidirectional converter is connected to each source. The output of the HESS is connected to the load through an inverter. The switches $S_{1}\left(S_{3}\right)$ and $S_{2}\left(S_{4}\right)$ will not conduct at the same time. $D_{1}, D_{3}$ are the on state duty ratios of the switches $S_{1}$ and $S_{3}$ respectively, and will always be between 0 and 1.

Table. I shows the terminologies used in the Fig. 2.

TABLE I

CiRCUIT TERMINOLOGY

\begin{tabular}{|l|l|}
\hline \multicolumn{1}{|c|}{ Terms } & \multicolumn{1}{c|}{ Circuit Component } \\
\hline$R_{b a t}$ & Parasite resistance of battery \\
\hline$R_{S C}$ & Parasite resistance of SC \\
\hline$C_{1}$ & Filter capacitance across battery \\
\hline$C_{2}$ & Filter capacitance across SC \\
\hline$V_{C_{l}}$ & Voltage across $C_{l}$ \\
\hline$V_{C_{2}}$ & Voltage across $C_{2}$ \\
\hline$L_{1}$ & Inductance series with battery \\
\hline$L_{2}$ & Inductance series with SC \\
\hline$i_{L_{l}}$ & Current through $L_{l}$ \\
\hline$i_{L_{2}}$ & Current through $L_{2}$ \\
\hline$R_{I}$ & Resistance in series with $L_{l}$ \\
\hline$R_{2}$ & Resistance in series with $L_{2}$ \\
\hline$V_{b a t}, V_{S C}$ & Battery voltage and SC voltage \\
\hline$C_{0}$ & DC bus capacitance \\
\hline$V_{0}$ & Bus voltage \\
\hline$i_{m}$ & Load current \\
\hline
\end{tabular}

The average model of the HESS can be given as [13],

$$
\begin{aligned}
\dot{V}_{1} & =-\frac{V_{C_{1}}}{R_{b a t} C_{1}}-\frac{i_{L_{1}}}{C_{1}}+\frac{V_{b a t}}{R_{b a t} C_{1}} \\
\dot{V}_{2} & =-\frac{V_{C_{2}}}{R_{s c} C_{2}}-\frac{i_{L_{2}}}{C_{2}}+\frac{V_{s c}}{R_{s c} C_{2}} \\
\dot{i}_{L_{1}} & =\frac{V_{C_{1}}}{L_{1}}-i_{1} \frac{R_{L 1}}{L_{1}}-\frac{V_{O}}{L_{1}}+V_{O} \frac{D_{1}}{L_{1}} \\
\dot{i}_{L_{2}} & =\frac{V_{C_{2}}}{L_{2}}-i_{2} \frac{R_{L 2}}{L_{2}}-\frac{V_{O}}{L_{2}}+V_{O} \frac{D_{3}}{L_{2}} \\
\dot{V}_{O} & =\frac{i_{L_{1}}+i_{L_{2}}}{C_{O}}-\frac{i_{m}}{C_{O}}-D_{1} \frac{i_{L_{1}}}{C_{O}}-D_{3} \frac{i_{L_{2}}}{C_{O}}
\end{aligned}
$$

\section{EnERgy MANAGEMEnt System (EMS)}

Energy management system (EMS) divides the powerdemand between battery and the SC according to the load requirement. For an electric vehicle motor will be the load, 


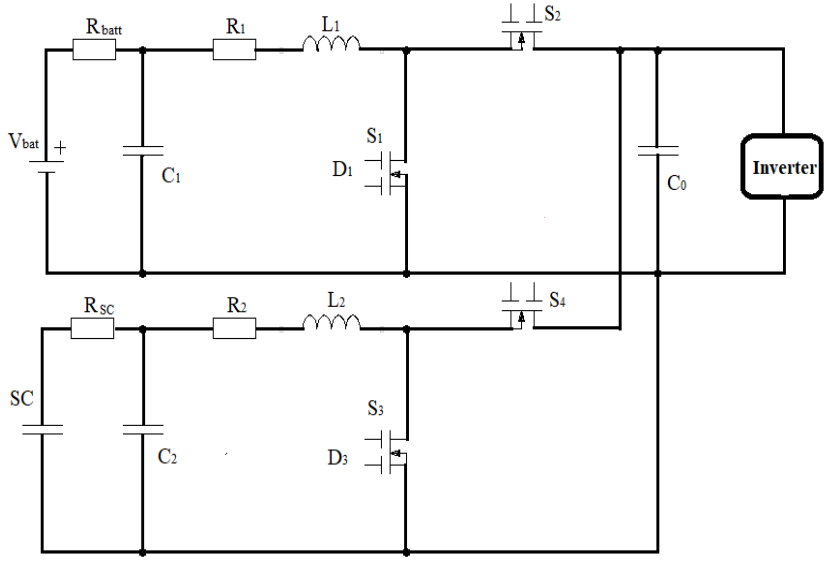

Fig. 2. Fully-Active HESS.

which is fed from inverter module powered from HESS. In EMS algorithm, battery reference current $i_{\text {bat-ref }}$ is generated from power demand, battery current and super capacitor voltage. The assumption take into consideration is that super capacitor voltage always above $50 \%$ of its maximum voltage rating.

EMS is realized by rule based approach and it is given in Fig. 3. Power-demand is the power required for the motor. If the demand for power becomes positive, then, need to check whether power-demand is greater than pre defined value Pmin, where P-min is the minimum power which battery can supply. If demand is greater than minimum value, then need to check the super capacitor voltage, in this step, system will check whether super capacitor have charge more than $50 \%$ of its full charge. If SC charge is more than 50\%, P-min will supply by battery and remaining will be provided by the SC. On the other hand, if the SC charge is less than the 50\% of power-demand will send by battery alone. If the powerdemand is less than P-min, then, check whether SC voltage is less than $50 \%$, if yes, battery will supply power required and if no, power-demand will be send by the battery and SC will get charged. During regenerative braking condition, SC will get charged from load.

\section{Super Twisting Algorithm}

The super twisting (ST) algorithm is a form of higher order sliding mode control, with relative degree one. It provides the controller with a continuous control action. This algorithm have a continuous function of sliding variable accompanying with an integration of discontinuous sliding variable.

ST algorithm can mathematically represents as follows,

Consider a $2^{\text {nd }}$ order system with state variables are in the form,

$$
\begin{aligned}
& \dot{x_{1}}=x_{2} \\
& \dot{x_{2}}=f(x, t)+g(x, t) u+d
\end{aligned}
$$

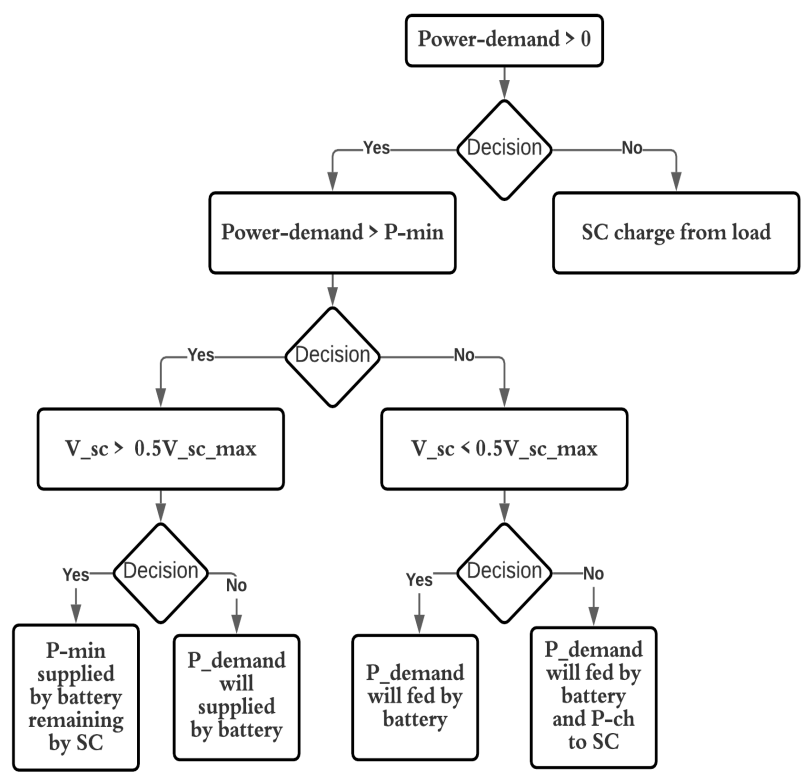

Fig. 3. Rule based energy management system.

and, sliding surface can represent as,

$$
\sigma=c_{1} x_{1}+c_{2} x_{2}
$$

The control law using super twisting algorithm for disturbance and chattering removal can be given as,

$$
\begin{aligned}
& u=-k_{1} \sqrt{|\sigma|} \operatorname{sign}(\sigma)+v \\
& \dot{v}=-k_{2} \operatorname{sign}(\sigma)
\end{aligned}
$$

Where, $\sigma$ is the sliding surface, and $k_{1}$ and $k_{2}$ are the constants which can defined a,

$$
\begin{aligned}
& k_{1}=1.1 k \\
& k_{2}=1.5 k
\end{aligned}
$$

Where, $k$ is the bound of disturbance $d$ [26].

The $2^{\text {nd }}$ order super twisting algorithm has the property of asymptotic convergence. A modified controller with finite time convergence capability is required, so an uniform continuous higher order sliding mode controller (UCHOSMC) can be used.

\section{UNIFORM CONTINUOUS HIGHER ORDER SLIDING MODE CONTROLLER (UCHOSMC)}

When compared to the super twisting algorithm, UCHOSMC shows finite time state convergences regardless of initial conditions. UCHOSMC is a hybrid of two controllers: one that will stabilise the system uniformly in the absence of disturbances, and another that uses an uniform super twisting algorithm which have a disturbance observation property. In this controller, the uniform super twisting controller takes over the effect of disturbances, and the uniform controller 
governs the closed loop system response. As a result, this approach yields an exact continuous control law and finite time convergence [27].

The UCHOSMC can be mathematically represents as below, Consider a system which can represent a chain of integrator as mentioned in (6).

The control $u$ can propose as,

$$
u=u_{O}+u_{D}
$$

Where $u_{O}$ is the control during the absence of a disturbance, $u_{O}$ will help in the convergence of the state to the desired value, irrespective of initial condition and $u_{D}$ is the ST algorithm to eliminate the disturbance.

So, for the given system $u_{O}$ can given as,

$$
u_{O}=-k_{1}\left|S_{1}\right|^{\alpha_{1}} \operatorname{sign}\left(S_{1}\right)-k_{2}\left|S_{2}\right|^{\alpha_{2}} \operatorname{sign}\left(S_{2}\right)
$$

where $\mathrm{S}$ can given as,

$$
\begin{aligned}
S_{i} & =x_{i}+\eta_{i}\left|x_{i}\right|^{\frac{1}{\alpha_{i}}} \operatorname{sign}\left(x_{i}\right) \\
\eta_{i} & =\frac{\chi_{i}}{k_{i}}
\end{aligned}
$$

Where $\mathrm{i}=1,2, \ldots, \mathrm{n}$, and $\chi$ and $k_{i}$ are the constant values.

The super twisting algorithm $u_{D}$ can given as,

$$
\begin{aligned}
u_{D} & =-k_{1} \phi_{1}(\sigma)+\dot{v} \\
\dot{v} & =-k_{2} \phi_{1}(\sigma)
\end{aligned}
$$

Sliding variable $\sigma$ defined as,

$$
\sigma=x_{n}-\int_{0}^{t} u_{O} d \tau
$$

and $\phi_{1}$ and $\phi_{2}$ will be equal to,

$$
\begin{aligned}
& \phi_{1}(\sigma)=\mu_{1}|\sigma|^{\frac{1}{2}} \operatorname{sign}(\sigma)+\mu_{2}|\sigma|^{\frac{3}{2}} \operatorname{sign}(\sigma) \\
& \phi_{2}(\sigma)=\frac{1}{2} \mu_{1}^{2} \operatorname{sign}(\sigma)+2 \mu_{1} \mu_{2}|\sigma|+\frac{3}{2} \mu_{2}^{2}|\sigma|^{2} \operatorname{sign}(\sigma)
\end{aligned}
$$

In (19) and (20) $\mu_{1}$ and $\mu_{2}$ should be greater than zero and by proper designing of constants control $u$ will be uniformly finite time stable. The converging condition is explained in [27].

\section{CONTROLler DESIGN FOR HESS}

In order to design controller for HESS consider state equations (1)- (5). In order to implement UCHOSMC, the state equation must be in the form (6) therefore, (1)-(5) is rearranged in order to satisfy the conditions of chain integrator. Design for battery side is as follows,

By integrating (2), will results $V_{l}$ which can given as,

$$
V_{1}=-\frac{\int V_{C_{1}}}{R_{b a t} C_{1}}-\frac{\int i_{L_{1}}}{C_{1}}+\frac{\int V_{b a t}}{R_{b a t} C_{1}}
$$

Substituting (21) into (2) will gives derivative of $i$.

Therefore,

$$
\begin{array}{r}
\dot{i}_{L 1}=-\frac{V_{O}}{L_{1}}+\frac{V_{O}}{L_{1}} D_{1}-\frac{R_{L 1}}{L_{1}} i_{L 1}-\frac{\int V_{C_{1}}}{R_{b a t} C_{1} L_{1}}- \\
\frac{\int i_{L 1}}{C_{1} L_{1}}+\frac{\int V_{b a t}}{R_{b a t} C_{1} L_{1}}
\end{array}
$$

Hence, state variable can taken as,

$$
\dot{i}_{L 1}=\dot{x_{1}}=x_{2}
$$

Taking derivative of (23) gives $\dot{x}_{2}$

$$
\begin{array}{r}
\ddot{i}_{L 1}=-\frac{\dot{V_{O}}}{L_{1}}+\frac{\dot{V_{O}}}{L_{1}} D_{1}-\frac{R_{L 1}}{L_{1}} \dot{i_{L 1}}-\frac{V_{C_{1}}}{R_{b a t} C_{1} L_{1}}- \\
\frac{i_{L 1}}{C_{1} L_{1}}+\frac{V_{b a t}}{R_{b a t} C_{1} L_{1}}
\end{array}
$$

The chain integration can given as,

$$
\ddot{i_{L 1}}=\dot{x_{2}}=x_{3}
$$

By rearranging (24)

$$
\begin{array}{r}
\ddot{i_{L 1}}=\left(-\frac{\dot{V_{O}}}{L_{1}}+-\frac{R_{L 1}}{L_{1}} i_{L 1}-\frac{V_{C_{1}}}{R_{b a t} C_{1} L_{1}}-\frac{i_{L 1}}{C_{1} L_{1}}+\right. \\
\left.\frac{V_{b a t}}{R_{b a t} C_{1} L_{1}}\right)+\frac{\dot{V}_{O}}{L_{1}} D_{1}
\end{array}
$$

Similarly for SC side design can be written as,

$$
\begin{aligned}
& \ddot{i_{L 2}}=-\frac{\dot{V_{O}}}{L_{2}}+\frac{\dot{V}_{O}}{L_{2}} D_{3}-\frac{R_{L 2}}{L_{2}} \dot{i}_{L 2}-\frac{V_{C_{2}}}{R_{b a t} C_{2} L_{2}}- \\
& \frac{i_{L 2}}{C_{2} L_{2}}+\frac{V_{b a t}}{R_{b a t} C_{2} L_{2}}
\end{aligned}
$$

By rearranging (27) gives,

$$
\begin{aligned}
& \ddot{i_{L 2}}=\left(-\frac{\dot{V_{O}}}{L_{2}}+-\frac{R_{L 2}}{L_{2}} \dot{i}_{L 2}-\frac{V_{C_{2}}}{R_{b a t} C_{2} L_{2}}-\frac{i_{L 2}}{C_{2} L_{2}}+\right. \\
& \left.\frac{V_{b a t}}{R_{b a t} C_{2} L_{2}}\right)+\frac{\dot{V}_{O}}{L_{2}} D_{3}
\end{aligned}
$$

Where(26) and (28) are in the form mentioned in (6).

Now UCHOSMC can implement to find the duty ratio $D_{l}$ for the system.

\section{A. Control design for battery side}

From (23) and (24) we have $\dot{x}_{1}$ and $\dot{x}_{2}$, next is to design control effort $u$. Here $D_{l}$ is taken as the control effort to regulate the current.

From (12) $u$ can be generated and from (13) $u_{O}$ for battery side can be obtained. $S_{1}$ and $S_{2}$ for (13) can be obtained as below,

$$
S_{1}=i_{L 1}+\eta_{1}\left|i_{L 1}\right|^{\frac{1}{\alpha_{1}}} \operatorname{sign}\left(i_{L 1}\right)
$$

and

$$
S_{2}=\dot{i_{L 1}}+\eta_{2}\left|\dot{i_{L 1}}\right|^{\frac{1}{\alpha_{2}}} \operatorname{sign}\left(\dot{i_{L 1}}\right)
$$

Thus $u_{O}$ can be generated. Next is to design super twisting algorithm as in (16) and (17). From (18) $\sigma$ can be given as,

$$
\sigma=\dot{i}_{L 1}-\int_{0}^{t} u_{0} d \tau
$$

And from (19) and (20) $\phi_{1}$ and $\phi_{2}$ can generated by substituting (31) into (19) and (20).

Adding $u_{O}$ and $u_{D}$ control effort $u$ will be obtained. 


\section{B. Control design for SC side}

Similarly as in battery control design from (23) and (24) we have $\dot{x}_{I_{-} S C}$ and $\dot{x}_{2} S C$, next is to design control effort $u_{-} S C$. Here $D_{3}$ is taken as the control effort to regulate the current.

From (12) $u_{-} S C$ can be generated and from (13) $u_{O_{-} S C}$ for battery side can be obtained. $S_{I_{-} S C}$ and $S_{2_{-} S C}$ for (13) can be obtained as below,

$$
S_{1 \_S C}=i_{L 2}+\eta_{3}\left|i_{L 2}\right|^{\frac{1}{\alpha_{3}}} \operatorname{sign}\left(i_{L 2}\right)
$$

and

$$
S_{2 \_S C}=\dot{i_{L 2}}+\eta_{4}\left|\dot{i}_{L 2}\right|^{\frac{1}{\alpha_{4}}} \operatorname{sign}\left(\dot{i_{L 2}}\right)
$$

Thus $u_{O_{-} S C}$ can be generated. Next is to design super twisting algorithm as in (16) and (17). From (18) $\sigma_{-} S C$ can be given as,

$$
\sigma_{-} S C=\dot{i}_{L 2}-\int_{0}^{t} u_{0 \_} S C d \tau
$$

And from (19) and (20) $\phi_{I_{-} S C}$ and $\phi_{2 \_S C}$ can generated by substituting (34) into (19) and (20).

Adding $u_{O_{-} S C}$ and $u_{D_{-} S C}$ control effort $u_{-} S C$ will be obtained.

\section{Simulation Results}

The effectiveness of the control algorithm is evaluated in MATLAB/Simulink. The circuit parameters taken for simulation are listed in the Table. II. In the simulation load is taken as current source equvalent to the load of EV. The values of constants in UCHOSMC are taken as in Table III.

TABLE II

HESS PARAMETERS

\begin{tabular}{|l|l|}
\hline \multicolumn{1}{|c|}{ Circuit Parameters } & \multicolumn{1}{c|}{ Range } \\
\hline $\mathrm{L}_{1}$, Inductance on battery side & $255 \mu \mathrm{H}$ \\
\hline $\mathrm{R}_{\mathrm{L} 1}$, Inductor series resistance & $0.256 \Omega$ \\
\hline $\mathrm{C}_{1}$, Capacitor across battery & $69 \mathrm{mF}$ \\
\hline $\mathrm{L}_{2}$, Inductance on Supercapacitor side & $188 \mu \mathrm{H}$ \\
\hline $\mathrm{R}_{\mathrm{sc}}$, SC pack resistance & $0.011 \Omega$ \\
\hline $\mathrm{R}_{\mathrm{L} 2}$, Resistance series with resistance & $0.161 \Omega$ \\
\hline $\mathrm{C}_{2}$, Capacitor across SC & $69 \mu \mathrm{F}$ \\
\hline $\mathrm{R}_{\mathrm{on}}$, MOSFET on time resistance & $21 \mathrm{~m} \Omega$ \\
\hline $\mathrm{C}_{\mathrm{o}}$, Load side capacitance & $14.85 \mathrm{mF}$ \\
\hline PWM frequency & $10 \mathrm{KHz}$ \\
\hline
\end{tabular}

The controller's main aim is to keep up with current references. The bus voltage is set to $240 \mathrm{~V}$, and the battery and SC voltages are held just below $240 \mathrm{~V}$, and the P-min is defined as $2800 \mathrm{~W}$. When the power demand reaches P-min, the SC discharges the energy, and during regenerative braking, the SC is charged from the load. The power demand for the

TABLE III

PARAMETERS OF UCHOSMC

\begin{tabular}{|c|c|c|c|c|c|c|c|}
\hline \multicolumn{7}{|c|}{ Battery Control Parameters } \\
\hline$\alpha_{1}$ & $\alpha_{2}$ & $\eta_{1}$ & $\eta_{2}$ & $\mathrm{~K}_{1}$ & $\mathrm{~K}_{2}$ & $\mu_{1}$ & $\mu_{2}$ \\
\hline 0.33 & 0.5 & 1 & 1 & 0.07 & 0.01 & 2 & 4 \\
\hline
\end{tabular}

\begin{tabular}{|c|c|c|c|c|c|c|c|}
\hline \multicolumn{1}{|c|}{ SC Control Parameters } \\
\hline$\alpha_{1}$ & $\alpha_{2}$ & $\eta_{1}$ & $\eta_{2}$ & $\mathrm{~K}_{1}$ & $\mathrm{~K}_{2}$ & $\mu_{1}$ & $\mu_{2}$ \\
\hline 0.33 & 0.5 & 1 & 1 & 0.7 & 0.6 & 2 & 4 \\
\hline
\end{tabular}

system can be seen in the Fig. 4. In drive cycle from time 0 to 2 seconds source will drive the load, and form 2 seconds to 3 seconds energy will flows from load to source, that is at regenerative braking condition, then 3 seconds to 5 seconds energy will flows from source to load.

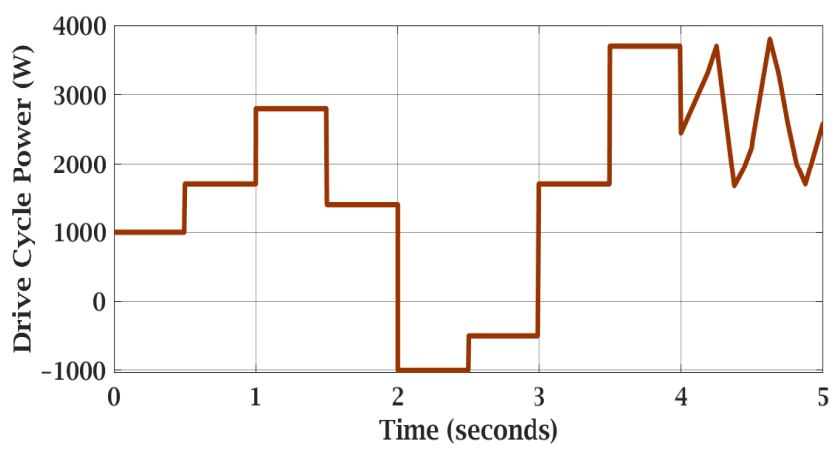

Fig. 4. Drive cycle for the system.

\section{A. Battery Performance}

In the HESS system the battery will be able to supply the power needed to load when the demand for power exceeds $2800 \mathrm{~W}, \mathrm{SC}$ along with battery supply required power. The battery stays idle during regenerative braking, and no action is taken at that time. Fig. 5 shows the battery current according to the reference generated from EMS, in figure battery current is strictly following the reference current.

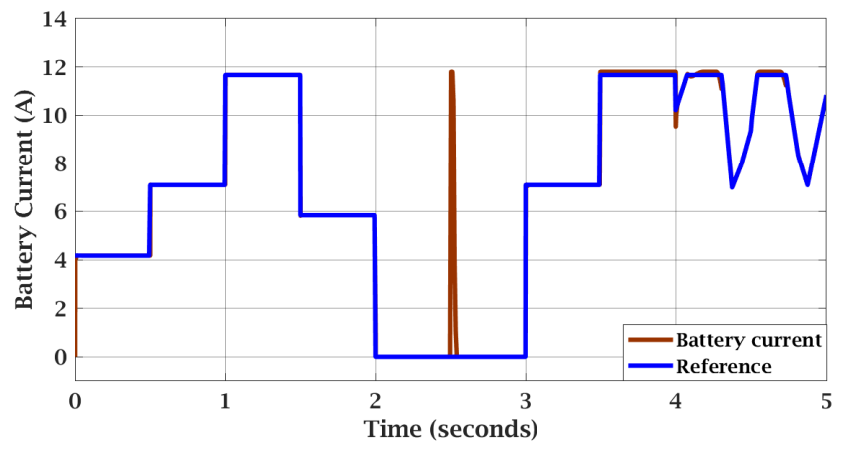

Fig. 5. Battery performance

Regardless of the initial state of the battery, the current will follow the desired value. Fig. 6 shows the battery current during various initial conditions, where $X(0)$ is the initial conditions.

\section{B. SC Performance}

$\mathrm{SC}$ is meant to meet high power demands and to recover energy during regenerative condition. SC remains idle when power demand is between $0 \mathrm{~W}$ and $2800 \mathrm{~W}$, and feeds energy to the load when power demand is greater than $2800 \mathrm{~W}$. In addition, when the power demand falls into the negative range, the SC receives energy from the load and is charged. Fig. 7 shows the current path of SC. 


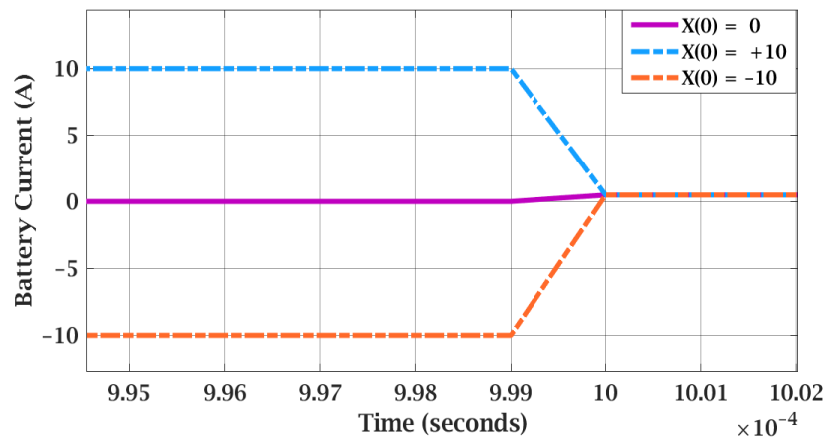

Fig. 6. SC performance

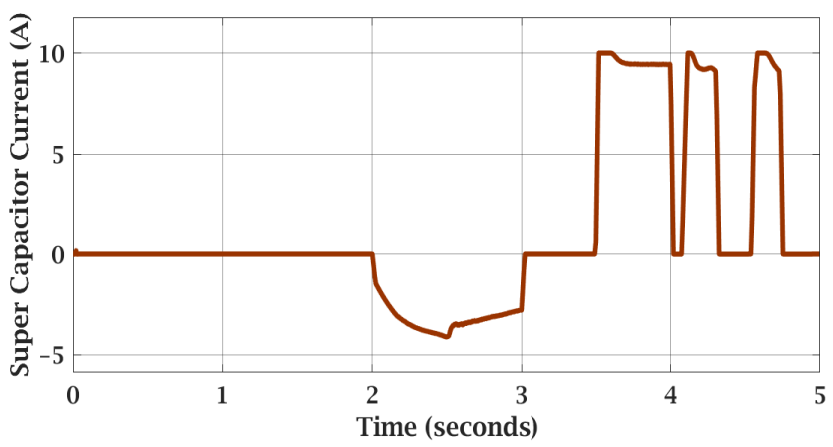

Fig. 7. SC performance

\section{Switching Pulses}

In this topology two duty ratios are generated using Equ. (12) one is for battery side converter and other is for SC side converter. Switching pulses are produced for the converter by comparing the duty ratios $\mathrm{D}_{1}$ and $\mathrm{D}_{3}$ with a sawtooth signal. The switching pulse for the battery side converter is shown in Fig. 8, and the switching pulse for the SC side is shown in Fig. 9.

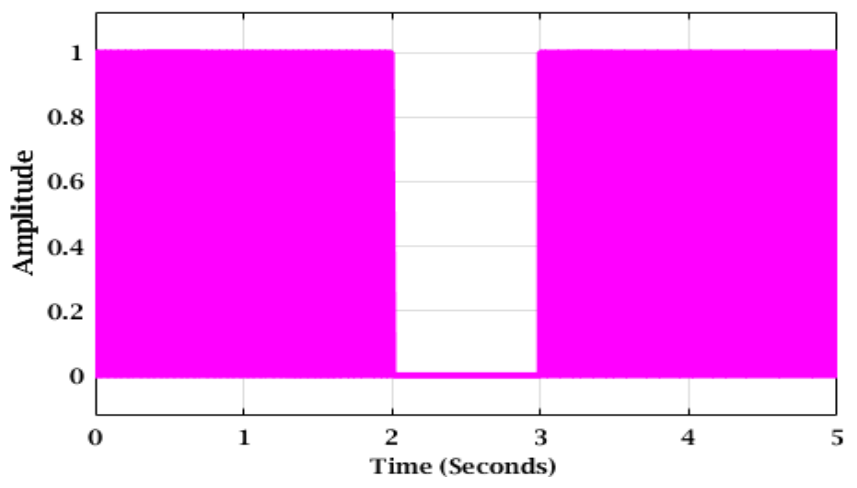

Fig. 8. Switching pulse for battery side converter

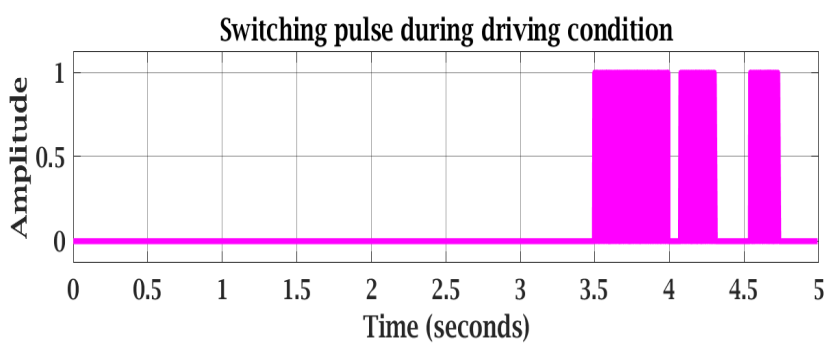

Switching pulse during regenerative condition

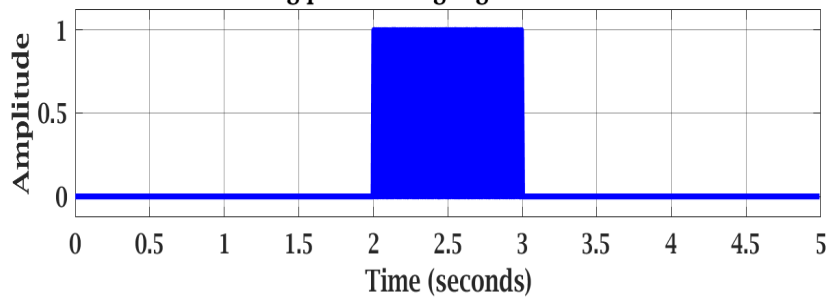

Fig. 9. Switching pulse for SC side converter

\section{CONCLUSION}

This paper proposes the application of new control technique for the fully active HESS in EVs. To track the reference current and achieve finite time convergence, an uniform continuous higher order sliding mode controller is applied here. The reference current is precisely regenerated by an energy management system (EMS) optimized using power demand, battery current and SC voltage. MATLAB/Simulink is used to verified the controller's effectiveness. Thus, the control strategy can be used effectively for HESS in EVs for efficient and reliable operation during varying load conditions.

\section{REFERENCES}

[1] L. H. Saw, H. M. Poon, H. S. Thiam, Z. Cai, W. Chong, N. A. Pambudi, and Y. J. King, "Novel thermal management system using mist cooling for lithium-ion battery packs," Applied Energy, vol. 223, pp. 146-158, Aug. 2018.

[2] C. M. Martinez, X. Hu, D. Cao, E. Velenis, B. Gao, and M. Wellers, "Energy management in plug-in hybrid electric vehicles: Recent progress and a connected vehicles perspective," IEEE Transactions on Vehicular Technology, vol. 66, no. 6, pp. 4534-4549, Jun. 2017.

[3] M. Bayati, M. Abedi, G. B. Gharehpetian, and M. Farahmandrad, "Shortterm interaction between electric vehicles and microgrid in decentralized vehicle-to-grid control methods," Protection and Control of Modern Power Systems, vol. 4, pp. 45-52, Feb. 2019.

[4] E. Vinot and R. Trigui, "Optimal energy management of hevs with hybrid storage system," Energy Conversion and Management, vol. 76, pp. 437-452, Dec. 2013.

[5] Z. Song, H. Hofmann, L. Jianqiu, J. Hou, X. Han, and M. Ouyang, "Energy management strategies comparison for electric vehicles with hybrid energy storage system," Applied Energy, vol. 134, p. 321-331, Dec. 2014.

[6] H. He, R. Xiong, K. Zhao, and Z. Liu, "Energy management strategy research on a hybrid power system by hardware-in-loop experiments," Applied Energy, vol. 112, pp. 1311-1317, Dec. 2013.

[7] B. Wang, J. Xu, R. Wai, and B. Cao, "Adaptive sliding-mode with hysteresis control strategy for simple multimode hybrid energy storage system in electric vehicles," IEEE Transactions on Industrial Electronics, vol. 64, no. 2, pp. 1404-1414, Feb. 2017. 
[8] J. P. Trovão, P. G. Pereirinha, H. M. Jorge, and C. H. Antunes, "A multilevel energy management system for multi-source electric vehicles an integrated rule-based meta-heuristic approach," Applied Energy, vol. 105, pp. 304-318, May 2013.

[9] B. Wang, J. Xu, B. Cao, and X. Zhou, "A novel multimode hybrid energy storage system and its energy management strategy for electric vehicles," Journal of Power Sources, vol. 281, pp. 432-443, May 2015.

[10] J. Blanes, R. Gutierrez, A. Garrigos, J. Lizan, and J. Cuadrado, "Electric vehicle battery life extension using ultracapacitors and an fpga controlled interleaved buck-boost converter," Power Electronics, IEEE Transactions on, vol. 28, pp. 5940-5948, Dec. 2013.

[11] R. A. Dougal, S. Liu, and R. E. White, "Power and life extension of battery-ultracapacitor hybrids," IEEE Transactions on Components and Packaging Technologies, vol. 25, no. 1, pp. 120-131, Mar. 2002.

[12] W. Lhomme, P. Delarue, P. Barrade, A. Bouscayrol, and A. Rufer, "Design and control of a supercapacitor storage system for traction applications," in Fourtieth IAS Annual Meeting. Conference Record of the 2005 Industry Applications Conference, vol. 3, Oct. 2005, pp. $2013-$ 2020.

[13] J. Cao and A. Emadi, "A new battery/ultracapacitor hybrid energy storage system for electric, hybrid, and plug-in hybrid electric vehicles," IEEE Transactions on Power Electronics, vol. 27, no. 1, pp. 122-132, Jan. 2012.

[14] M. B. Camara, H. Gualous, F. Gustin, A. Berthon, and B. Dakyo, "Dc/dc converter design for supercapacitor and battery power management in hybrid vehicle applications-polynomial control strategy," IEEE Transactions on Industrial Electronics, vol. 57, no. 2, pp. 587-597, Feb. 2010.

[15] Z. Amjadi and S. S. Williamson, "Power-electronics-based solutions for plug-in hybrid electric vehicle energy storage and management systems," IEEE Transactions on Industrial Electronics, vol. 57, no. 2, pp. 608-616, Feb. 2010.

[16] R. Carter, A. Cruden, and P. J. Hall, "Optimizing for efficiency or battery life in a battery/supercapacitor electric vehicle," IEEE Transactions on Vehicular Technology, vol. 61, no. 4, pp. 1526-1533, May. 2012.

[17] Battery-supercapacitor Energy Storage. Swedan: Department of Energy and Environment Chalmers University of Technology, Jun. 2008.

[18] M. Hannan, F. Azidin, and A. Mohamed, "Multi-sources model and control algorithm of an energy management system for light electric vehicles," Energy Conversion and Management, vol. 62, pp. 123-130, Oct. 2012.

[19] A. L. Allegre, A. Bouscayrol, and R. Trigui, "Influence of control strategies on battery/supercapacitor hybrid energy storage systems for traction applications," in 2009 IEEE Vehicle Power and Propulsion Conference, Sep. 2009, pp. 213-220.

[20] Z. Song, H. Hofmann, J. Li, X. Han, and M. Ouyang, "Optimization for a hybrid energy storage system in electric vehicles using dynamic programing approach," Applied Energy, vol. 139, pp. 151-162, Feb. 2015.

[21] O. Veneri, C. Capasso, and S. Patalano, "Experimental investigation into the effectiveness of a super-capacitor based hybrid energy storage system for urban commercial vehicles," Applied Energy, vol. 227, pp. 312-323, Oct. 2018.

[22] Z. Song, J. Hou, H. Hofmann, J. Li, and M. Ouyang, "Sliding-mode and lyapunov function-based control for battery/supercapacitor hybrid energy storage system used in electric vehicles," Energy, vol. 122, pp. 601-612, Mar. 2017.

[23] B. Wang, J. Xu, D. Xu, and Z. Yan, "Implementation of an estimatorbased adaptive sliding mode control strategy for a boost converter based battery/supercapacitor hybrid energy storage system in electric vehicles," Energy Conversion and Management, vol. 151, pp. 562-572, Nov. 2017.

[24] H. Jung, H. Wang, and T. Hu, "Control design for robust tracking and smooth transition in power systems with battery/supercapacitor hybrid energy storage devices," Journal of Power Sources, vol. 267, pp. 566575, Dec. 2014

[25] S. V. Emelyanov, S. K. Korovin, and A. Levant, "High-order sliding modes in control systems," Computational Mathematics and Modeling, vol. 7, p. 294-318, Jul. 1996.

[26] P. Ramesh Kumar and B. Bandyopadhyay, "Variable gain super twisting controller for the position stabilization of stewart platform," IFAC Proceedings Volumes, vol. 47, no. 1, pp. 115-121, Mar. 2014.

[27] S. Kamal, R. Kumar P, A. Chalanga, J. Goyal, B. Bandyopadhyay, and L. Fridman, "A new class of uniform continuous higher order sliding mode controllers," Journal of Dynamic Systems Measurement and Control, vol. DS-18-1187, Oct. 2019. 